\title{
Numerical Modeling of Independent versus Dependent Tensile -Frictional Strength Behavior of Synthetic Rocks with Non-continuous joints
}

Abdelkareem Alzo'ubi ( $\sim$ abdelkareem@gmail.com )

Abu Dhabi University https://orcid.org/0000-0003-3449-7089

Omer Mughieda

Abu Dhabi University

Manish Kewalramani

Abu Dhabi University

\section{Research Article}

Keywords: tensile strength, dependent, independent, numerical, rock, yielding

Posted Date: June 23rd, 2021

DOI: https://doi.org/10.21203/rs.3.rs-180009/v1

License: (c) (i) This work is licensed under a Creative Commons Attribution 4.0 International License.

Read Full License 


\section{Abstract}

The failure mechanisms of non-continuous jointed rocks under compression loading is of great importance for the rock mechanics community; it plays an important role in understanding the fracturing pattern, the type of the fractures, and the strength of the rock mass under investigation. In this paper, the relationship between the tensile and frictional strength of jointed rock samples is investigated by numerical modeling. Previously tested samples were used to simulate the behavior of artificial jointed rock numerically under axial loading by using two strength criteria; the first assumes that tensile failure reduces shear strength parameters to their residual values (dependent behavior, Model 1 ) and the second assumes that tensile failure will not cause the shear strength parameters to be reduced to their residual values (independent behavior, Model 2). The numerical model, in this paper uses, Mohr-Coulomb shear strength criterion with parameters of cohesion, friction, and tensile strength cut-off as tested in the laboratory. These artificial rock samples contains open-joints with the same inclination but with different bridge's inclinations of $45^{\circ}, 60^{\circ}$, and $75^{\circ}$. These samples were tested in the laboratory under incremental uniaxial loading until failure while monitoring displacement and rupturing development. As the stress concentration increased, curvilinear yielding (wing crack) started near or at the joint tips and propagated and stopped or coalesced to form a continuous rupture surface. The numerical model showed that tensile stress concentration caused wing crack initiation due to stress flow around the pre-existing non-persistent open joints. The yielding behavior of the numerical simulations - under the two tensile strength failure criteria - and the laboratory tests shows good agreement for the three samples. However, when the shear strength and tensile strength parameters are independent, the results showed strong and significant agreement between the laboratory tests and the numerical models in terms of the yielding path, width of failure zone, and the uniaxial strength. In this all compressive load environment, stress flow caused tensile stress concentration near the joint tip and according to the results of this paper the tensile yielding should not force the shear strength parameters to go to their residual values.

\section{Introduction}

In nature, rock slopes are highly heterogeneous and are associated with many unknowns such as the state of the stress, the structures inside the rock mass, and the strength parameters. These factors among others control the analysis and design of rock slopes and failure mechanisms (Alzo'ubi, 2016a). Intact rock masses might only occur at extreme depths, and near-surface rock masses are full of discontinuities; flaws, joints, and flaws with different scales. Moreover, these discontinuities might be persistent or non-persistent ones and they might also be opened or closed with or without infillings which might control the behavior of these joints and ultimately the rock mass. Although faults most of the time are persistent discontinuities, the majority of joints, fractures, and flaws are non-persistent and usually, rock bridges must exist between discontinuities segments. These bridges control the ultimate strength of the rock mass but including them in the analysis can't be done easily and numerical methods should be used. So, to understand the rock mass behavior and strength, we need to be able to model the rock mass numerically as accurately as possible by using the right approach and benchmark with laboratory results 
and extrapolate for new cases. To understand the level of complexity of this problem, one must note that it is commonly believed that the majority of rock discontinuities fail in shear Terzaghi (1962), however, rock bridges arguably fail in tension (Alzo'ubi et al 2007, Cho et al, 2008), depending on the mechanism of loading and the stress path in the field or the laboratory.

Terzaghi (1962) pointed out that structurally controlled slopes normally fail by shear sliding along one or more continuous discontinuities whereas, in non-structurally controlled slopes failure is a complicated process and involves a failure in both the discontinuity and the intact material. Moreover, the size of the rock mass also plays a role in the type of failure; the hypothesis that one discontinuity dictates a slope failure is valid only on a small scale (few meters), whereas, large-scale slopes failure is a complex process that requires deep analysis. As a result of this complexity, Lajtai (1969b) focused on the nonpersistent nature of rock discontinuities and conducted direct shear tests on the Plaster of Paris to simulate intact rock blocks; Lajtai's blocks contained rectangular voids to represent the non-persistent nature of the joints. He pointed out that for non-persistent joints, the minor principal stress in the rock bridge is tensile even if the all-around stresses are compressive. These tensile stresses are responsible for forming the fractures in the rock bridges and tensile fracturing dominates the mode of failure in the rock bridge even though his joints were aligned and this geometry doesn't encourage extensile stresses. As normal stress increased, the failure mode progressively became dominated by shear mechanisms (Alzo'ubi, 2012). Based on his finding, Lajtai suggested that the failure of rock containing intact rock bridges between joints could be represented by a nonlinear envelope whose nonlinearity occurred because of the non-uniform mobilization of friction. At low normal stress, the tensile strength controlled the failure while at high normal stress; the frictional strength dominated the failure process. This finding implies that tensile and frictional strength may not mobilize simultaneously. Later, Hajiabdolmajid et al (2002) presented the cohesion weakening friction strengthening model (CWFS) to show that the relationship between these two strength parameters mobilization, however, they ignored the tensile strength behavior or the connection between the frictional and tensile strength, i.e. do these two types of strength mobilize at the same strain or not at the same strain, from a practical point of view this creates a difficulty on the design of rock structures or their behavior.

Moreover, in near-surface rocks such as in rock slopes and shallow rock structures, the low confinement stress environment dominates the stress state and the discontinuities are usually open non-persistent ones that lead to stress flow around the joints and tensile stress concentrations. So, many researchers conducted uniaxial compressive tests with or without monitoring the displacement (see Alzo'ubi 2016b) to understand the behavior of jointed rock mass and the stresses responsible for causing the bridge's failure at low confinement stress. This paper aims to examine if the tensile strength and frictional strength are dependent on each other (Model 1), i.e. tensile failure will lead to reducing the shear strength parameters to their residual values or independent (Model 2), i.e., tensile failure should not force reducing the shear strength parameters to their residual values. The Finite Element Method allows for modeling by using the two approaches, however, MODEL 1 causes shear failure to occur at the instance of tensile failure due to their dependency and reduction of the shear strength parameters to their residual values happens at the onset of tension failure, this might be true for cohesion but not for friction. Meanwhile, in 
MODEL 2 the tensile failure will not force reduction of the shear strength parameters to their residual values and shear/tensile failure is allowed but independently and might occur at the same or different strain level.

This research purposes to determine the difference between the two approaches of modeling adopted usually in numerical modeling (Rocscience, 2020) to simulate rock mass behavior and investigate the most valid behavior by comparing the results of the two models with the laboratory tests of three samples made of artificial rocks that simulate sandstones.

In this experiment, the wing cracks development and yielding surface were monitored for the three samples with bridge inclinations of $45^{\circ}, 60^{\circ}$, and $75^{\circ}$. Besides, the entire coalescence process, and stresses responsible to cause failure, and the minor and major stress are monitored and discussed. The numerical model in this paper uses the Mohr-Coulomb criterion and brittle behavior with cohesion, friction, and tensile strength to assess the right approach of modeling.

\section{Previous Work}

Many researchers have argued that rock joints in large-scale slopes are rarely continuous, and that intact rock exists between the joint segments [e.g., Terzaghi (1962), Lajtai (1969a), Jennings (1970), Ladanyi and Archambault (1980), Einstein et al. (1983)]. These researchers reasoned that a failure in rock slopes must pass through the intact rock to form a kinematically admissible release surface. This process occurs progressively, and failure will propagate from the pre-existing rock joints through the intact material. Some stepping may be required to form a rupture surface as well. Lajtai (1969b), Jennings (1970), Ladanyi and Archambault (1980), and Shen et al. (1995) showed that tensile stress concentrations initiate the stepping at the rock bridges and near the tips of the joints. Moreover, they reasoned that the bridge between the joint segments fails in tension and that the tensile strength plays an important role in the failure mechanism of rock slopes in a low-confinement stress environment but did not discuss if tensile and shear strength are dependent or independent.

To investigate the jointed rock behavior, Lajtai (1969a) conducted a series of tests using the plaster of Paris. His blocks, containing rectangular voids to represent the discontinuous nature of joints, were subjected to direct shear at various normal stresses. He showed that the stress state under low normal stress might trigger fracturing inside a rock mass, as the tensile stress exceeds the tensile strength of the bridge. And he suggested that cohesion and friction mobilization might occur at a different strain level. This concept can be extended to the tensile strength mobilization and the relation between the tensile strength mobilization and shear strength parameters mobilization.

Moreover, to understand the behavior under compression, Lajtai (1974) performed a uniaxial compression on the plaster of Paris specimens. He found that "tensile" fractures were initiated first and then were followed by "normal" and "inclined shear." The tensile stress around the tip of the pre-existing joint initiated the wing cracks first and was followed by shear fracturing. The direct shear and the uniaxial tests showed the critical role of the tensile strength and tensile fracturing in rock mass strength. Ingraffea 
and Heuze (1980) tested two rock types, Granodiorite and Limestone specimens, under uniaxial loading and found similar results to Lajtai's. With this in mind, the investigation of the stresses responsible for initiating these cracks is essential as well as the tensile-shear strength relation.

When Horri and Nemat-Nasser (1985) performed different tests on Columbia resin samples containing pre-existing joints to examine the effect of confining pressure on the crack propagation regime. They found that under axial compression, tension cracks were initiated at the tips of the pre-existing joints, grew with increasing compression, and became parallel to the direction of the loading. When a lateral compression also existed, the crack growth was stable and stopped at some finite crack length which leads to the understanding that tensile failure might occur while shear failure might be delayed due to mobilization of the shear strength parameters after the tensile strength. As small lateral tension was applied, the crack growth, after a certain length, became unstable. This finding is considered to be the fundamental mechanism of axial splitting observed in uniaxially compressed rock specimens under compression and showed the effect of extensile fracturing, not a shear failure. However, it was not clear the type of stresses who were responsible for those cracks initiation at that time.

In 1990, Reyes and Einstein (1990) conducted uniaxial tests on small gypsum specimens that simulate the rock mass, with two inclined offset joints. Their results showed that the fracture growth depended on the geometry of the joints. They pointed out that the wing cracks grew first and then were followed by secondary crack growth, which led to coalescence between the non-overlapping flaws. On the other hand, coalescence between the overlapping flaws in the specimens occurred through the tensile wing crack growth and at a load higher than the coalescence load measured for the non-overlapping flaws. The relationship between tensile failure and shear failure should be examined.

Later, Shen et al. (1995) performed a series of uniaxial compression tests on small gypsum specimens with closed and opened joints. The results showed that the coalescence of inclined fracture was due to shear failure and/or tensile failure. The final shape of the fracturing and the stresses responsible for that failure were highly dependent on the position of the joints.

When Bobet and Einstein (1998) performed uniaxial and biaxial tests on gypsum with pre-existing open and closed joints, they found that two types of cracks occurred: tensile wing cracks and secondary cracks, which were initiated as shear cracks in a plane roughly co-planar with the flaw. However, secondary cracks also propagated out of the plane as either tensile or shear cracks. In 2002, Sagong and Bobet (2002) tested specimens made of gypsum under uniaxial compression to study the fracturing process. They found that the wing cracks were tensile ones that were initiated at an angle with the flaw and propagated stably towards the direction of the maximum compression. The secondary cracks were shear cracks that initially propagated along their plane in a non-stable manner. This paper will examine the behavior of artificial rocks numerically and compared with the laboratory results to examine the two types of modeling approaches, model1, and model 2.

In the following, we present the experimental results of three pre-existing joint configurations. 


\section{Experimental Work}

Alzo'ubi (2001) conducted uniaxial loading tests on synthetic rocks made of silica sand, cement, and water to simulate the behavior of sandstone. The material elastic properties were determined from the stress-strain diagram of the intact synthetic rocks as shown in Fig. 1. This material simulates the behavior of sandstone in terms of the strength properties and elastic properties, while the material elastic and strength properties are shown in Table 1. To study the failure mechanisms of rock bridges as their orientation changes, this synthetic material was used to prepare samples with the following dimensions; $63.5 \mathrm{~cm}, 27.9 \mathrm{~cm}$, and $20.3 \mathrm{~cm}$. A special mold as shown in Fig. 2a was made to prepare samples with different joints configuration as shown in Fig. $2 \mathrm{~b}$. The samples were then tested under uniaxial loading while monitoring cracks initiation, stress, and deformation by using LVDTs and a data acquisition system. The samples as shown in Fig. $2 \mathrm{~b}$ contained two pre-existing non-persistent open joints, where the joint angle ( $\beta$ ) was kept constant at $45^{\circ}$ and the bridge angle (a) were changed at $15^{\circ}$ increments from coplanar joints to overlapped joints.

It is worth mentioning that, at each bridge orientation two samples were tested and their behavior was monitored; if any discrepancy in the behavior was found a third sample was prepared and tested for verification purposes. Moreover, to test the unconfined compressive strength (UCS) of the mix, three cylindrical samples from the same mixture of each sample at the time of mixing were taken, cured, and tested under uniaxial compression. The average UCS obtained from all of the samples ranged from 9 to $12.5 \mathrm{MPa}$ with an average overall of all the samples sets at $10470 \mathrm{kPa}$.

In this paper, only three samples with three joints configurations were used to be examined numerically. The experimental results and the observed failure process are presented for three samples with bridge inclinations (a) of $45^{\circ}, 60^{\circ}$, and $75^{\circ}$.

\subsection{Sample with $a=45^{\circ}$}

The first sample in this study has a bridge inclination of $45^{\circ}$, Fig. 3 shows the sample before and after testing. In this test, the wing cracks were initiated at the joint tip and propagated in the direction of axial loading as shown in Fig. 4. A secondary crack was initiated at the inner joint tips followed by the rupture surface formation due to the propagation of the secondary cracks in a curvilinear fashion as shown in Fig. 4. Notice the curvature nature and direction of the rupture surface is concaving up as shown in Fig. 3 as well as in Fig. 4.

The rupture surface, in this test, was examined carefully and showed little debris formation and the morphology of the surface was rough, which is an indication of tensile failure in the bridge area. Figure 5 shows the inside of the sample at which a curvilinear rough rupture surface is formed at the bridge area, the uniaxial compression stress and deformation along the joint, and the bridge was monitored and showed that the joint has a great effect on the strength of the entire sample. Figure 6 shows the deformation of the joint and the bridge in the normal direction as measured by the LVDTs shown in Fig. 3, 
the amount of dilation in the joint is very high $(-0.65 \mathrm{~mm})$ compared to the dilation at the joint $(-0.2 \mathrm{~mm})$. This dilation is an indication of extensile cracks developed in the bridge area.

\subsection{Sample with $a=60^{\circ}$}

At this test the bridge angle was $60^{\circ}$, Fig. 7 shows the sample before and after testing. The wing cracks were initiated and continued to grow until the rupture surface formation in the bridge area. At this joint configuration, the wing cracks were initiated at the joint tip and propagated in the direction of axial loading in the same manner as the previous samples which indicate splitting due to extensile stresses. A secondary crack was initiated at the center of the bridge area first and then followed by secondary cracks at the inner joint tips as shown in Fig. 8. The rupture surface in the bridge area is formed due to the propagation and coalescence of the secondary cracks; the failure progression is shown in Fig. 8.

After investigation of the tested sample, no debris found in the bridge area, and the rupture surface had a rough nature, this morphology coincides with a rupture surface formed by tensile stresses and not a shear one. As appears in Fig. 9, the sample's interior is very similar to the rupture surface of the wing crack which always initiates under tensile stresses. This rough rupture surface is usually formed due to tensile dilation rather than sliding failure which produces a smooth surface and debris. The displacement at the joint and the tip showed similar behavior as the sample with $a=45^{\circ}$. Dilation was recorded at both the bridge and joint but with a much higher magnitude at the bridge, this indicates the tension concentration at the bridge and extensile fracturing.

\subsection{Sample with $a=75^{\circ}$}

As in the previous two samples, wing crack was initiated first near the joint tips. However, the inner wing cracks at the inner joint's tips propagated in the loading direction in a curvilinear fashion toward the other joint's tip to form a core like a rupture surface as shown in Fig. 10. Figure 11 shows a schematic diagram of the fracturing progress as observed in the laboratory. The core that was formed at the bridge area had a tensile rupture surface morphology that coincides with Lajtia's (1969a) description of tensile fracturing, Fig. 12 shows the two sides of the sample after failure. The rupture surfaces formed on both sides of the core are rough ones with no debris found. The displacement recorded by the LVDTs (Fig. 10), shows the dilation of the bridge similar to the above two samples.

In the following, the material properties and the numerical analysis of these three samples are presented to investigate the behavior of the sample under uniaxial loading under the two failure criteria that are Model 1 and Model 2. This would help in determining the internal behavior of the sample and the correct model that will reproduce the observed behavior of the samples in the laboratory.

\section{Material Properties And Unconfined Test Model}

The synthetic material was tested in the laboratory to establish its properties; Table 1 shows the mechanical properties of the artificial rock. Meanwhile, the unconfined compressive strength of the mix was tested for each sample as mentioned earlier. To establish the cohesion, of the mix to be used in this numerical simulation; a numerical parametric study was conducted by simulating the Unconfined 
Compressive Strength (UCS). The values of the cohesion were varied and the unconfined compressive strength of the intact material was monitored. As mentioned earlier, the Mohr-Coulomb strength model along with the finite element method $(\mathrm{RS} 2,2018)$ was used to perform the UCS as shown in Fig. 13. The boundary conditions were free at the sides and displacement boundary condition was applied in 40 consecutive stages. The figure shows the boundary conditions as well as the finite element mesh. The cohesion value was increased while monitoring the UCS as shown in Fig. 14, the cohesion at a UCS of 10.48 MPa is $2.88 \mathrm{MPa}$. Moreover, the original mix had a tensile strength of $1 / 10$ to $1 / 12$ of the UCS, and a friction angle of $32^{\circ}$, so, a tensile strength of $0.875 \mathrm{MPa}$ and friction angle of $32^{\circ}$ was used in the UCS numerical model as well as the rest of the numerical models. The modulus of elasticity, and poisons ratio, are shown in Table 1.

Table 1

Laboratory and Numerical simulation model mechanical properties

\begin{tabular}{|llll|}
\hline Properties & Laboratory & Numerical Peak & Residual \\
\hline$\Phi^{\circ}$ & 32 & 32 & 32 \\
\hline Cohesion (MPa) & varied & 2.88 & 0.0 \\
E (GPa) & 11 & 11 & 11 \\
\hline v & 0.17 & 0.17 & - \\
\hline Tensile Strength MPa & 0.875 & 0.875 & 0 \\
\hline UCS (MPa) & 10.47 & 10.48 & - \\
\hline
\end{tabular}

\section{Numerical Model}

In this paper, the finite element method is utilized to investigate the difference between the two criteria of tensile failure association with frictional strength usually used in numerical modeling (RS2, 2018). The first one is the dependent tensile-shear strength behavior (Model 1) and the second is the independent behavior of the two (Model 2). In Model 1 adapted in this study, the tensile failure of material reduces the shear strength parameters to their residual values, i.e. if a tensile failure occurs then the shear strength parameters will be reduced automatically to their residual values as assumed. However, in Model 2 the tensile strength does not reduce the shear strength parameters to their residual values but rather shear failure will do. To determine which model should be used, the laboratory results were compared with the two numerical models (Model 1 and Model 2) for the above three samples. To establish which model (model 1 or model 2) explain the results better, three criteria were used; yielding path, the width of the yielding zone, and the normalized uniaxial compressive strength of the jointed samples to the unconfined compressive strength of the mix. 
The finite element model adapted for this study is based on (Alzo'ubi 2016) numerical model; Fig. 15 shows the model, mesh, boundary conditions, and the details of the non-persistent joints which are explicitly modeled as an open excavation with no support. The boundary conditions in this model are; rollers at the sides of the steel plates, and displacement boundary condition at the top, and the bottom of the sample as shown in Fig. 15.

To better monitor the behavior in the area of interest i.e. the bridge area; six node element was used for the finite element mesh with four times higher mesh density around the joints and bridge between the joints as shown in Fig. 15. The Mohr-Coulomb failure criterion with tension cut-off was used for both models (Model 1 and Model 2). For each new sample with a non-persistent joint configuration, a first numerical simulation was conducted assuming Model 1 behavior, and a second numerical simulation was conducted assuming Model 2 behavior.

Furthermore, to simulate axial loading that was used in the laboratory a displacement boundary condition was applied gradually in forty consecutive stages to enable monitoring of the behavior as smooth as possible while keeping the simulation time reasonable. The yielding of the sample, in shear and/or tension, was monitored until a continuous yielding surface formed in the bridge area as discussed in the following section.

\section{Numerical Simulation Results And Discussion}

This part aims to verify which model of strength behavior is more suitable to describe the behavior of the laboratory investigation. The three samples with different joints configurations are simulated numerically to show the details of yielding in the bridge area, the unconfined compressive strength at failure, and the width of yielding based on two the assumptions of dependent versus independent tensile-frictional strength behavior. For each sample configuration, the two models of behavior (Model 1 and Model 2) are simulated and compared with the laboratory results.

\subsection{Inner Tips aligned Sample with $a=45^{\circ}$}

\subsubsection{Model 1:}

As the downward displacement increased multiple wing cracks were initiated near the tip of the joints. These wing cracks were initiated due to the flow of stresses around the open joints to form a tensile stress environment in the bridge area as shown in Fig. 16 and a second wing crack developed as well. In model 1, 566 of the failed elements yielded under shear and tension; and only 9 elements failed in tension. The rupture surface developed from the secondary cracks that were initiated at the joint tip as shown in Fig. 17. Moreover, a second major wing crack developed in the bridge area as shown in Figs. 16 and 17, this was not observed in the laboratory experiments as shown in Fig. 17. The main observation can be seen by comparing the numerical simulation with the laboratory results; the yielding zone in the numerical model is concaving down meanwhile in the laboratory experiment its concaving up. The second is that the yielding zone in the numerical model is thick one once compared to the thin rupture 
surface observed in the laboratory and shown in Fig. 17, on average 32 elements yielded across any horizontal line at the bridge area. Note that all elements yielded in tension and shear, in the figure shear failure is denoted by $(x)$ and tension failure is denoted by $(0)$.

\subsubsection{Model 2:}

In this model, independent tensile-shear behavior, as the downward displacement increased two major wing cracks were initiated near the tip of the joints. As shown in Fig. 18, these wing cracks initiated due to the flow of stresses around the open joints that forms a tensile stress environment in the bridge area in model 2, unlike model 1, the wing crack developed under tensile failure, and the failed elements yielded under tension as shown in the figure. As stresses increased due to the increasing displacement, yielding started at the bridge area and 452 elements failed in tension while 50 elements failed in shear mode. The shear failure was focused near the inner tips where the stress concentration occurred due to the flow around the joint tips. Meanwhile, the bridge failed in pure tension and the rupture surface concaving up which coincides with the laboratory results, compares the numerical model with the laboratory results in Fig. 19. As for the thickness of the yielding zone, it is narrower than the observed in the Model 1 simulation, this mimics the failure surface observed in the laboratory. Moreover, on average 10 elements yielded across any horizontal line at the bridge area compared to 32 in the Model 1 simulation.

\subsection{Sample with $a=60^{\circ}$}

\subsubsection{Model 1:}

In this sample, the bridge angle (a) is $60^{\circ}$. As in the previous model, we simulated the laboratory test in 40 stages to enable monitoring of the rupture surface initiation and propagation. As a result, the wing cracks failed in shear and tension as shown in Fig. 20 , also the bridge between the joints failed in mixed mode shear and tension which indicated that tension failure forced shear failure due to their dependency. In this model, the rupture surface concaved down as the sample before, and that was not observed in the tested sample in the laboratory. Moreover, at the bottom joint's inner tip notice the small gap between the wing crack and the rupture surface in the numerical model. The laboratory sample shows a large gap as shown in Fig. 20. Moreover, in the laboratory, the rupture surface did not show any sign of shear failure as observed by Alzo'ubi, 2002., however, the numerical model showed shear failure. Moreover, the yielding zone is thick and not as narrow as the laboratory results.

\subsubsection{Model 2:}

In this sample, the bridge angle (a) is $60^{\circ}$. As in the previous model, we simulated the laboratory test in 40 stages to enable monitoring of the rupture surface initiation and propagation. As a result, the wing cracks failed in tension as shown in Fig. 21. In the figure, the results show tension failure dominates the bridge and no elements yielded in shear or mixed mode. Comparing the independent behavior model 2 with the dependent behavior in model 1 , the rupture surface concaved up and that was not observed in the tested sample in the laboratory (Fig. 21). Moreover, at the bottom joint's inner tip notice the large gap between the wing crack and the rupture surface in the numerical model as well as in the laboratory sample (Fig. 
21). This pure tension failure in the numerical simulation mimics the pure tension failure observed in the laboratory by Alzo'ubi, 2002. Moreover, the yielding zone is thin and as narrow as the laboratory results.

\subsection{Sample with $a=75^{\circ}$}

\subsubsection{Model 1:}

As loading progressed, the elements near the tip yielded in shear/tension mode to form a rupture surface in the bridge area. Figure 22 shows two stages of yielding progress in Model 1 along with the sample for comparison.

Note that most elements yielded in shear ( $\mathrm{x}$ ) and tension (o). In this Figure, the stress contours show that tensile stresses dominated the bridge and the joint tip areas (dark shaded areas) at which wing cracks developed. While some compressive stress concentration existed at the joint tip opposite to the wing crack initiation tip, more importantly, only $1 \%$ of the elements yielded in pure shear and the rest of the elements failed in mixed mode despite the all tensile stresses environment in the bridge area; notice that the minor principal stress values in the figure. Although the cracks near the inner tips of the joints developed to form the rupture surface similar to the one observed in the laboratory, the thickness of these cracks and the rupture surface is way much wider than the one observed in the laboratory, see Fig. 22 lab sample.

\subsubsection{Model 2:}

To examine whether yielding occurred under tension, shear, or both; Model 2 simulation was done. The yielding path was similar to the first model at which cracks were initiated under high tensile stress concentration and propagated under the negative minor stress environment. Figure 23 shows the yielding elements in the area of concern near the joints and bridge areas. In the Figure, dark shaded areas show negative minor stresses, and light-shaded areas show positive minor stresses. As observed in the simulation, the yielding process was initiated under a high concentration of tensile stress at the preexisting joint tips. Through monitoring the development of the yielding elements we noticed that as the tensile stress approaches the tensile strength of the artificial rocks, elements yielded in the direction of the axial load. Few elements (26 elements) yielded in shear near the joint tip but did not propagate, see Fig. 23. This behavior coincides with laboratory results and shows that tensile yielding, at this bridge inclination, controlled the behavior of rocks with pre-existing joints. The numerical model in these experiments showed similar behavior and tensile yielding in the rock bridge as observed by Lajtai (19969a). Moreover, he showed that for non-persistent rock joints under shearing load, the minor principal stress in the rock bridge is tensile even if the all-around stresses are compressive;

Although Mughieda and Omar (2008) used the finite element method to study the stresses around open non-persistent rock joints. They used the linear elastic model to simulate the behavior of brittle artificial rock. They showed that the tensile stresses were concentrated only around the joint tip, this might be due to the limitations in the constitutive model that they used to generate tensile stresses inside the rock bridges; they used an elastic analysis to model a clear case of fracturing behavior. 
As shown in Fig. 23, the rupture surface developed in model 2 consists of one or two tension failure elements. Figure 24 shows the complete yielding process from initiation at the tips until failure in the bridge. The yielding started at the joint tip and progressed in this numerical model in the same manner as observed at the laboratory (see Fig. 11). The stresses flowed around the pre-existing open joints and created a tensile stress environment. Once the tensile stresses exceeded the tensile strength of the material, yielding started near the joint's tips. At the inner joint tips, the elements yielded in curvilinear fashion and continued to grow toward the other joint's inner tip under negative minor stress (tension). This yielding process formed a core in the bridge area similar to the one observed in the Laboratory, compare Fig. 23 with Figs. 10, 11, and 12. A thoroughgoing very thin yielding surface formed as a result of pure tension stresses that existed ahead of the yielding elements, and the thickness of this rupture surface coincides with the experimental results unlike Model 1 simulation shown in Fig. 22.

\subsection{Uniaxial Compressive Strength and Stress Path:}

Although the above discussion showed clearly the advantages of using the proposed Model 2 over Model 1 in numerical simulation of brittle rock failure, the axial compressive strength normalized to the unconfined compressive of the mix $\left(\sigma_{1 f} / \sigma_{u c}\right)$ was monitored for the three samples. Figure 25 shows the $\sigma_{1 f} / \sigma_{\mathrm{uc}}$ results of the laboratory samples compared to model 1 and model 2 values. The independent behavior (Model 2) shows very close results to the laboratory ones in terms of values and trends. The dependent behavior (Model 1) shows a huge discrepancy with the laboratory results. Essentially brittle failure is controlled by tension as noticed by Lajtai (1969), and Choi et al (2008). So, tensile failure should not control shear failure, but rather independent behavior should be used.

Moreover, the major and minor stress in the bridge area ahead of yielding elements was monitored to show the stress path, and the developed tensile stresses in the models. Figure 26 shows $\sigma_{1 f}$ and $\sigma_{3 f}$ for two samples to show the stress behavior as loading progresses. The independent Model 2 behavior shows greater tensile stresses in the bridge area as shown in the figure. This modeling approach allowed for higher tensile stresses to develop before failure which in turn allowed the Model 2 samples to carry a higher load and have higher uniaxial compressive strength than Model 1 samples, as shown in Figs. 22 and 26 .

\section{Conclusion}

This paper utilizes the finite element code to investigate two modes of modeling; dependent tensilefriction behavior and independent tensile-friction behavior. The initiation and propagation of the wing cracks were traced to enhance our understanding of this phenomenon and determine the stress environment (tension or compression) responsible for elements yielding and yielding surface formation in the bridge between open joints. The Model 1 behavior (dependent) was less accurate in predicting the yielding surface shape, the thickness of the yielding surface, and the uniaxial compressive strength. In terms of the bridge's yielding surface formed in Model 1 (dependent) versus Model 2 (independent tensilefriction behavior)), the rupture surface in Model 1 shows a thick band of yielded elements and straight-to- 
concave down rupture surface which was not observed in the laboratory. The numerical model with Model 2 (independent behavior) mimics the true behavior observed in the laboratory.

The uniaxial compressive strength was also compared with the results of the two modeling approaches. The results showed that Model 2 predicted with high accuracy the laboratory results while Model $1 \mathrm{did}$ not predict the trend nor the magnitudes of the uniaxial compressive strength. Upon investigation of the major and minor principal stresses along the path of yielding the results showed that Model 2 allowed for more confinement and higher tensile stresses than the ones observed in Model1 which resulted in higher compressive strength and closer results to the laboratory results.

So, the reduction of friction and cohesion to their residual values upon tensile behavior will not accurately model the rock mass behavior as shown in this analysis. And also, the failure zone developed in Model 1 is wide once compared to the narrow failure zone observed in Model 2. Dependent behavior between tensile and frictional behavior did not simulate accurately the width of the rupture surface observed in the laboratory experiments.

The analysis showed that pre-existing joints with bridge inclinations of $45^{\circ}, 60^{\circ}$, and $75^{\circ}$ coalesced by tensile yielding. Moreover, the observed yielding initiation and development in the laboratory were compared with the finite element models, and excellent agreement was achieved with Model 2 behavior.

\section{Declarations}

Funding (Not applicable)

Conflicts of interest/Competing interests: we declare that we have no conflict of interest of competing interest

\section{Availability of data and material (Available)}

Code availability (Not Applicable)

\section{References}

Alzo'ubi, A. K., (2001). Fracture mechanisms of open offset rock joints under uniaxial loading, M. Sc. thesis, Jordan University of Science and Technology, Irbid, Jordan.

Alzo'ubi, (2016a) "Rock slopes processes and recommended methods for analysis", DOI: 10.21660/2016.25.34052, International Journal of Geomate, pp. 2520-2527, Vol.11, June 2016

Alzo'ubi, A.K., C. D. Martin and D. M. Cruden, (2007) "A discrete element damage model for rock slopes" 1st Canada-U.S. Rock Mechanics Symposium, June 2007, In Rock Mechanics, Meeting Society's Challenges and Demands, edited by E. Eberhardt, D. Stead, and T. Morrison, vol. 1, pp. 503-510. Vancouver, B.C 
Alzo'ubi, A.K., (2012) "Modeling of Rocks Under Direct Shear Loading by Using Discrete Element Method", AHU J. of Engineering \& Applied Science, 4 (2) 2012

Alzo'ubi, A.K., (2016b) "Rock slopes processes and recommended methods for analysis", DOI: 10.21660/2016.25.34052, International Journal of Geomate, pp. 2520-2527, Vol.11, June 2016

Cho, N., Martin, C. D., Sego, D. C., 2007, A clumped particle model for rock, https://doi.org/10.1016/j.ijrmms.2007.02.002, International Journal of Rock Mechanics and Mining Sciences, pp. 997-1010, Volume 44, issue 7, 2007

V. Hajiabdolmajid, P. K. Kaiser, and C. D. Martin, "Modelling brittle failure of rock," International Journal of Rock Mechanics and Mining Sciences, vol. 39, no. 6, pp. 731-741, 2002

Bobet, A., Einstein, H., 1998. Fracture coalescence in rock-type materials under uniaxial and biaxial compression. Int. J. Rock Mech. Min. Sci. 35, 863-888.

Einstein, H., Venezaino, D., Baecher, G., and O'reilly, K., 1983. The effect of discontinuity persistence on rock slope stability. International journal of rock mechanics and mining science and geomechanics abstract, 20(5): 227-236.

H. Horii and S. Nemat-Nasser, 1985. "Elastic Fields of Interacting Inhomogeneities," International Journal of Solid and Structures, 21, pp. 731-745.

Jennings, J., 1970. A mathematical theory for calculation of the stability of slopes in open cast mines. In: Planning of Open Pit Mines, pp. 87-102. Johannesburg.

Reyes, O. and Einstein, H.H. 1990. Stochastic and centrifuge modeling of jointed rock, Part I-Fracturing of jointed rock, Final Report submitted to the Air Force office of Scientific Research and Air Force Engineering Services Center, U.S.A.

Ladanyi, B. and Archambault, G., 1980. Direct and indirect determination of shear strength of rock mass. In Preprint Number 80-25, AIME Annual Meeting. Littleton: Society of Mining Engineering of A.I.M.E., Las Vegas, Nevada.

Lajtai, E., 1969a. Mechanics of second order faults and tension gashes. Geological society of American Bulletin, 80: 2253-2272.

Lajtai, E., 1969b. Strength of discontinuous rocks in direct shear. Geotechnique, 6:499-515.

Lajtai, E., 1974. Brittle fracture in compression. International Journal of Fracture, 10(4): 525-536.

Mughieda, O., and Alzo'ubi, A., 2004. Fracture mechanisms of offset rock joints-a laboratory investigation. Geotechnical and Geological Engineering, 22: 545-562. 
Mughieda and Omar, 2008. Stress Analysis for Rock Mass Failure with Offset Joint. Geotechnical and Geological Engineering. DOI 10.1007/s10706-008-9188-1

Rocscience, 2016. Rocscience Software products, DIPS, SWEDGE, SLIDE and PHASE2. Rocsience Inc., Toronto

Shen, B., Stephanson, O., Einstein, H. H., and Ghahreman, B., 1995. Coalescence of fractures under shear stresses in experiments. Journal of Geophysical Research, 100: 5975-5990.

Terzaghi, K., 1962. Stability of steep slopes on hard unweathered rock. Geotechnique, 12: 251-270.

Hajiabdolmajid, V., Kaiser, P., and Martin, C., (2003). "Mobilized strength components in brittle failure of rock". Geotechnique, 53: 327-336.

Bahaaddini, M., Hagan, P., Mitra, R., \& Hebblewhite, B. K. (2016). Numerical Study of the Mechanical Behavior of Nonpersistent Jointed Rock Masses. International Journal of Geomechanics, 16(1).

\section{Figures}
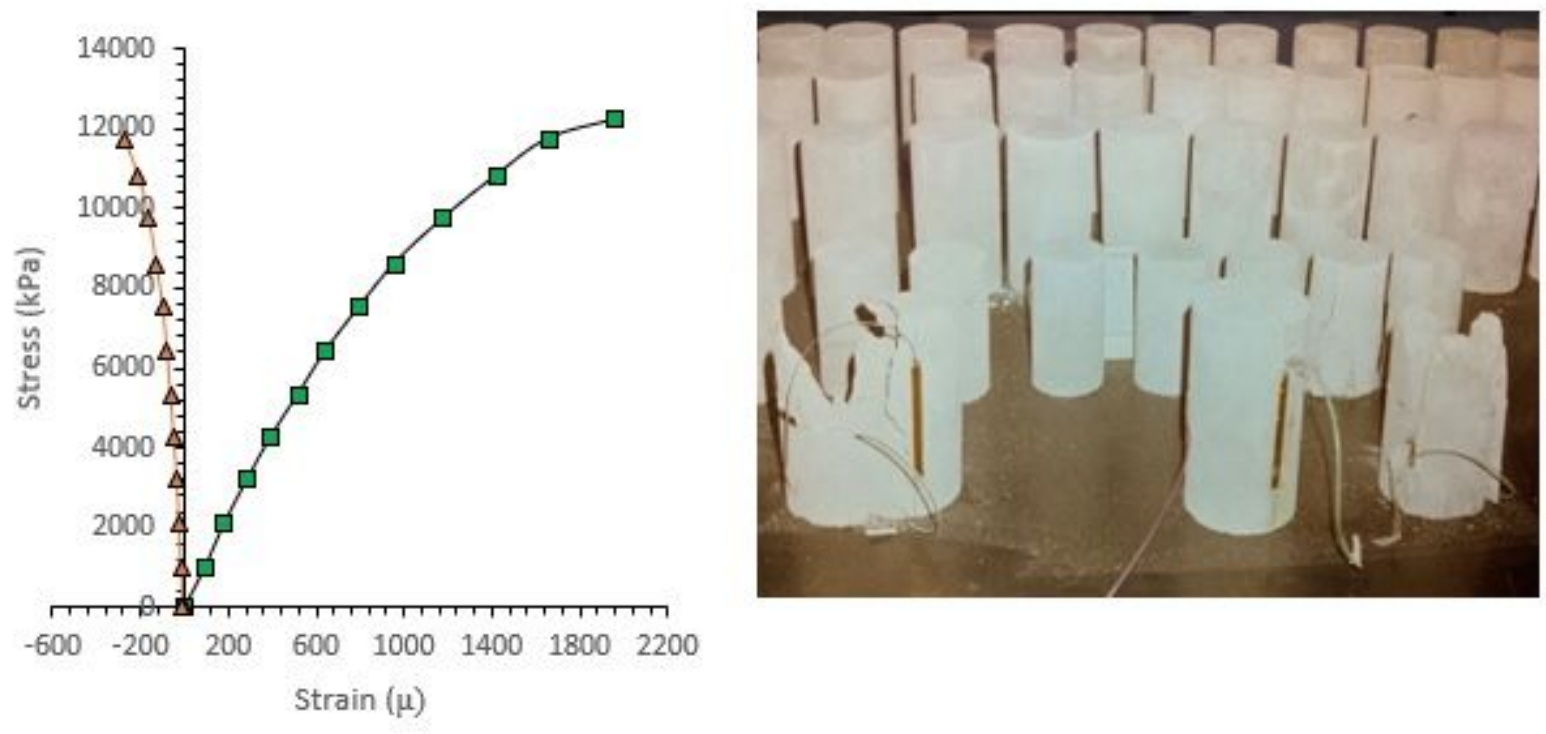

\section{Figure 1}

stress-strain diagram of the synthetic rock mix and tested samples 

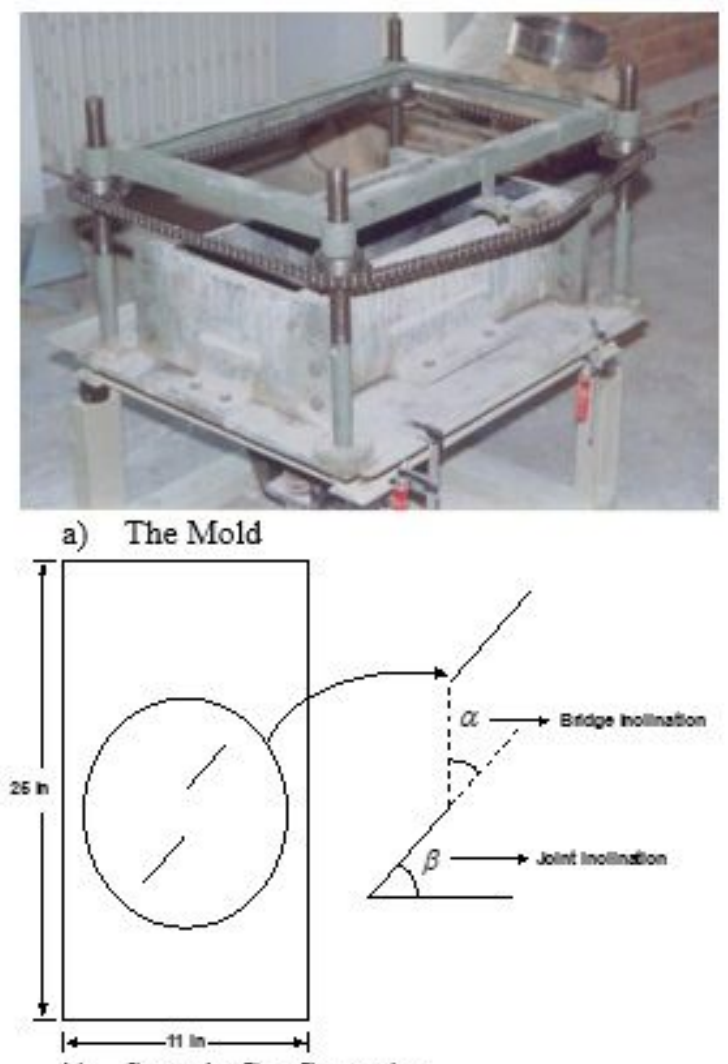

b) Sample Configuration

Figure 2

The mold used in preparing the samples in this study and the joint configuration

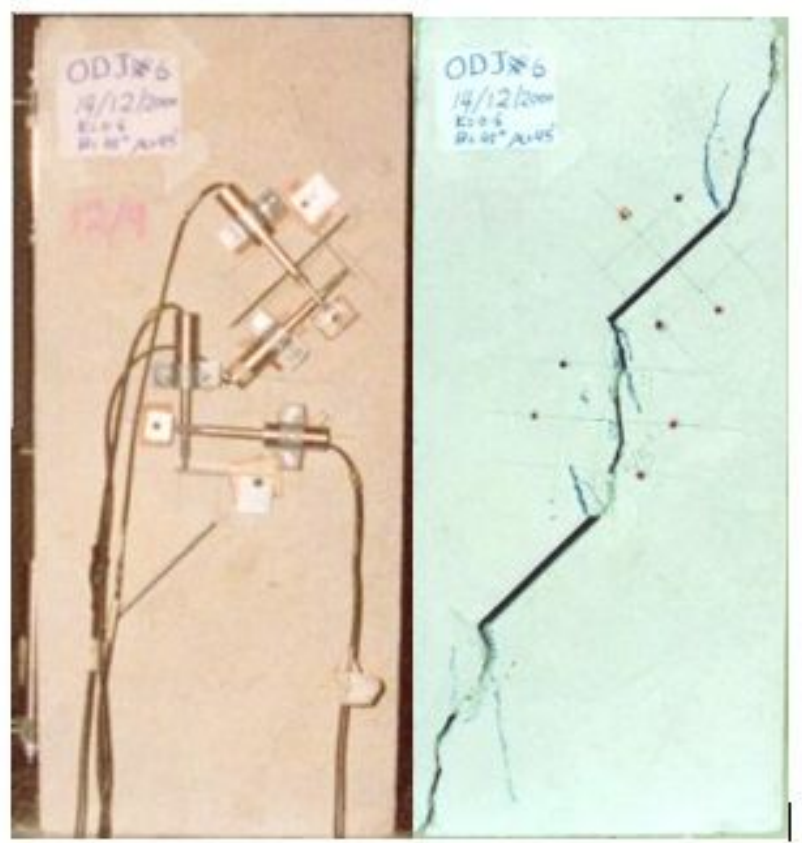

Figure 3

Rupture surface for the sample with $a=45^{\circ}$ 


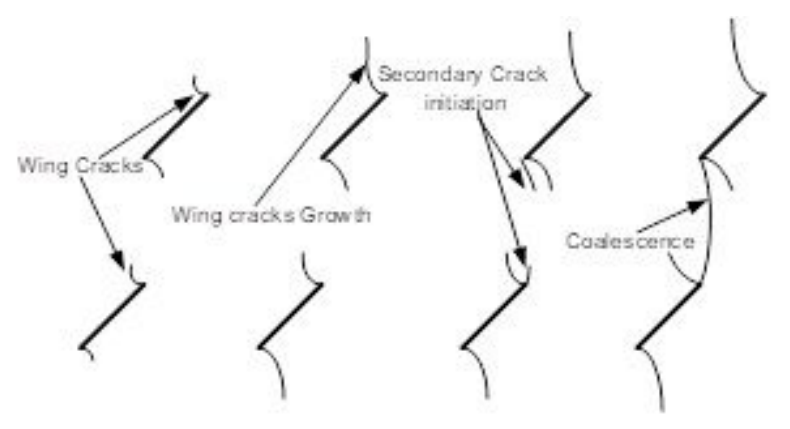

Figure 4

Coalescence process for the sample with $a=45^{\circ}$

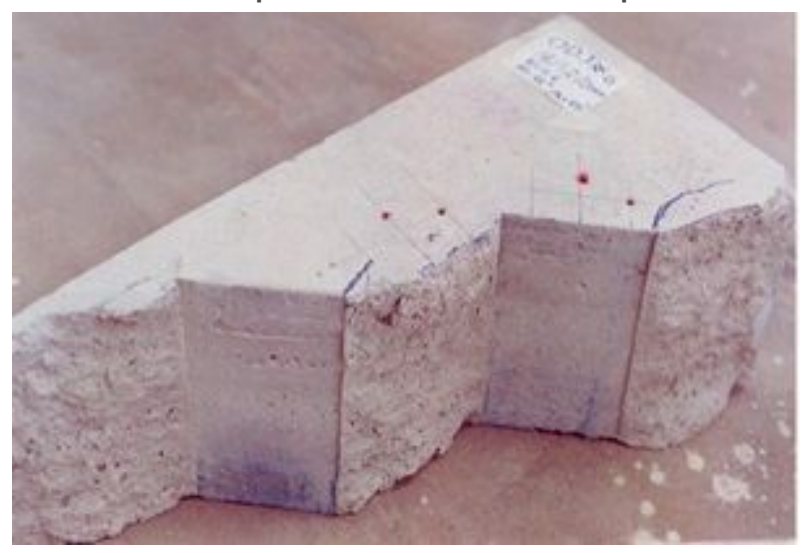

Figure 5

Internal rupture surface for the sample with $\alpha=45^{\circ}$

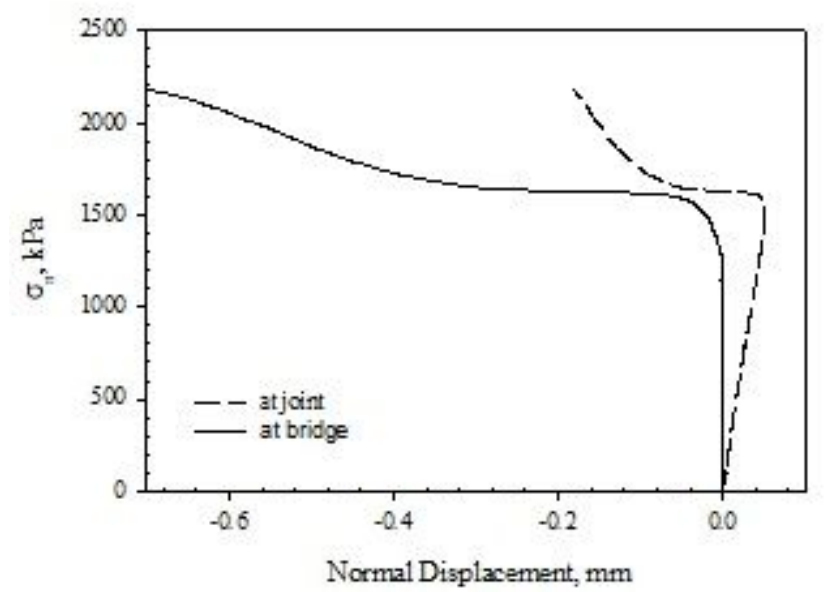

Figure 6

normal stress versus deformation at the bridge and joint, $a=45^{\circ}$ 


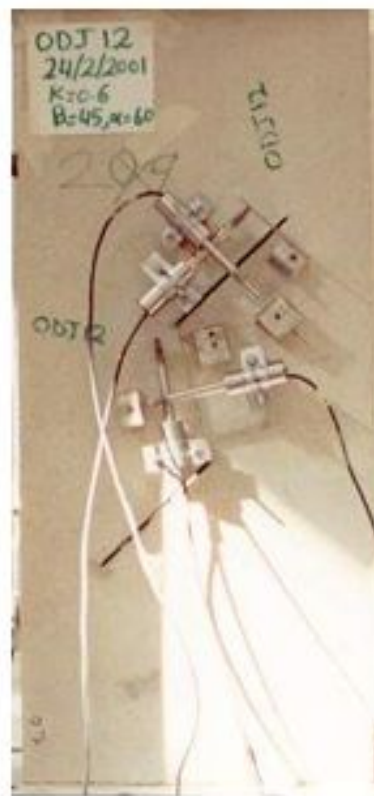

a) Pre-testing

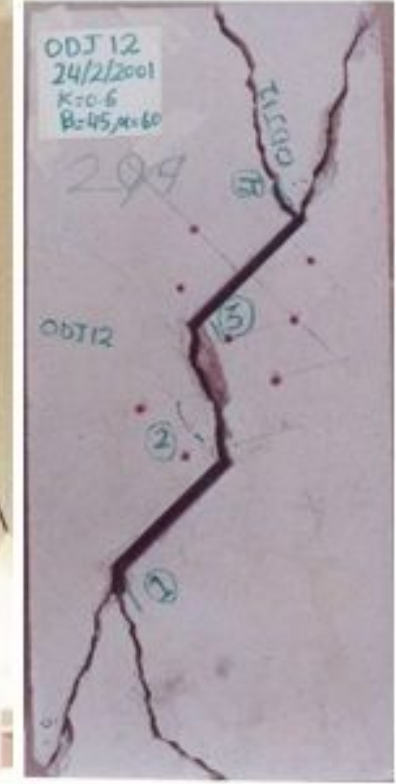

b) after testing

\section{Figure 7}

$60^{\circ}$ bridge sample before and after failure

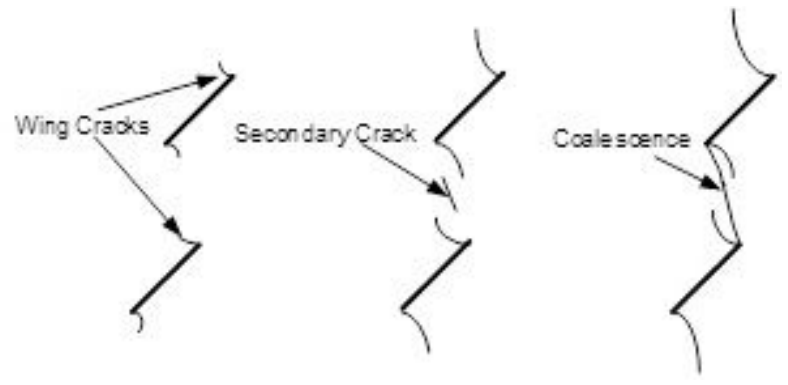

Figure 8

Coalescence process for the sample with $a=60^{\circ}$

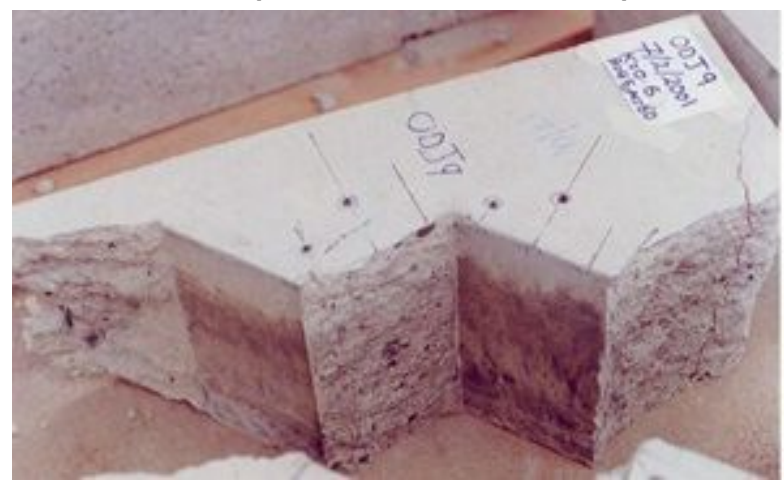

Figure 9

Internal rupture surface for the sample with $a=60^{\circ}$ 


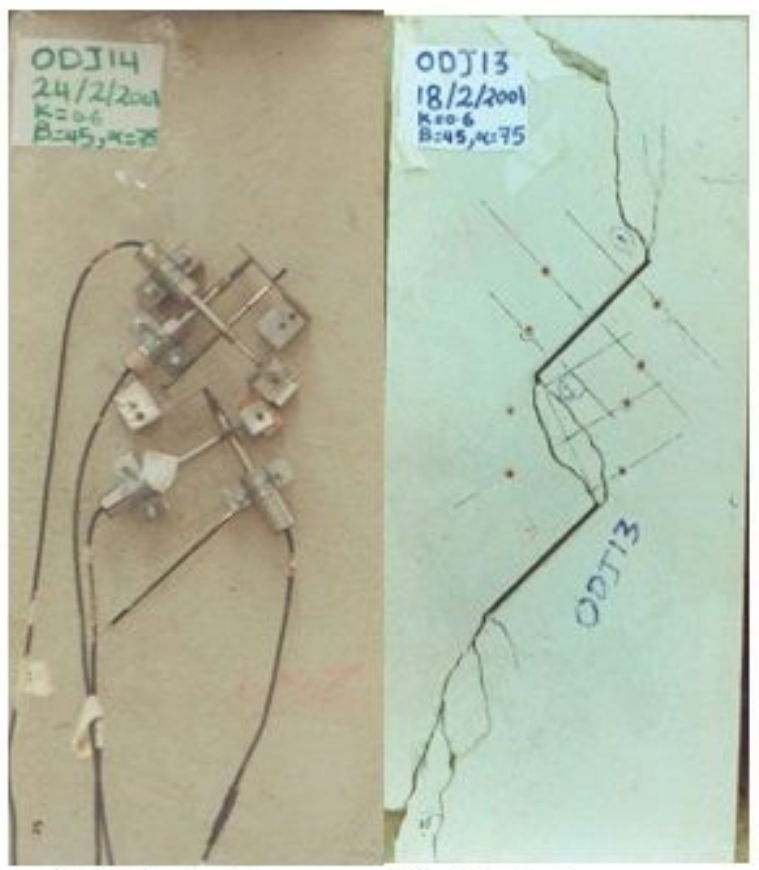
b) Pre-testing
b) after testing

Figure 10

$75^{\circ}$ bridge sample before and after failure
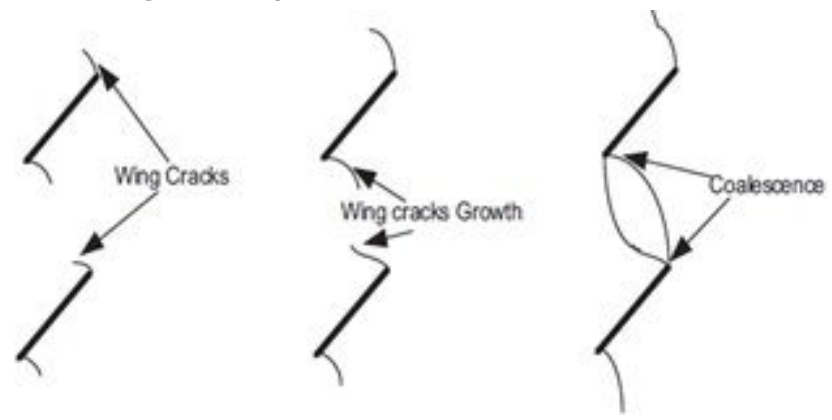

Figure 11

The fracturing of the $75^{\circ}$ sample as observed in the lab. 


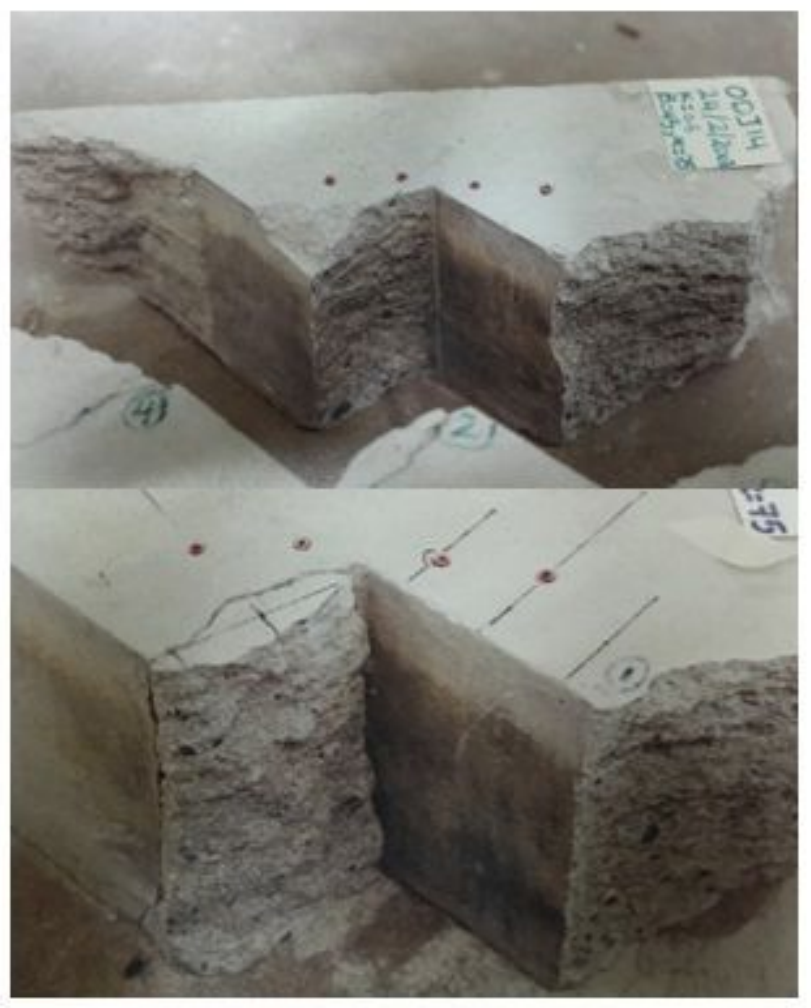

Figure 12

The two sides of the $75^{\circ}$ sample after failure
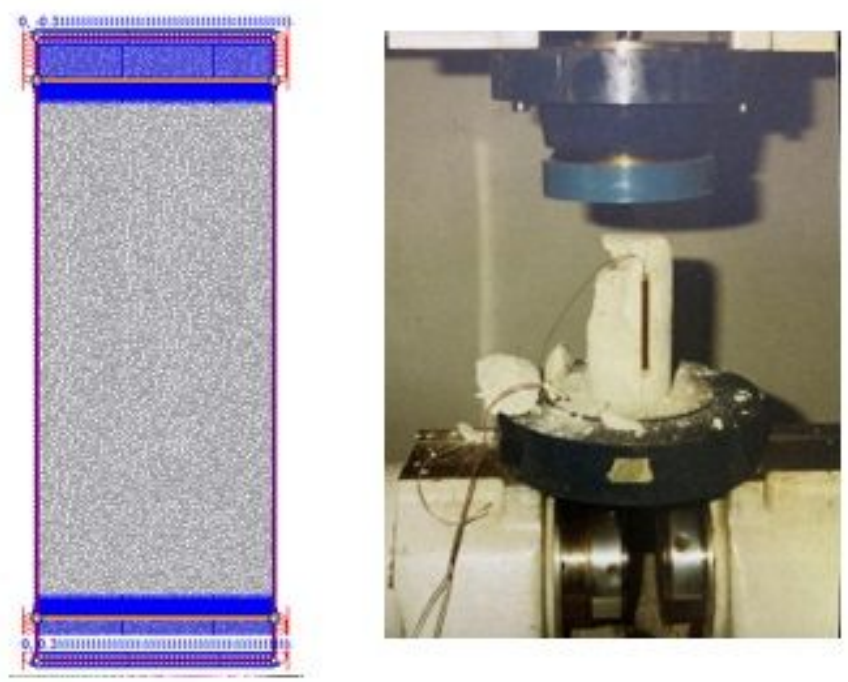

Figure 13

The unconfined compressive strength numerical model, mesh, and the boundary conditions and the lab test 


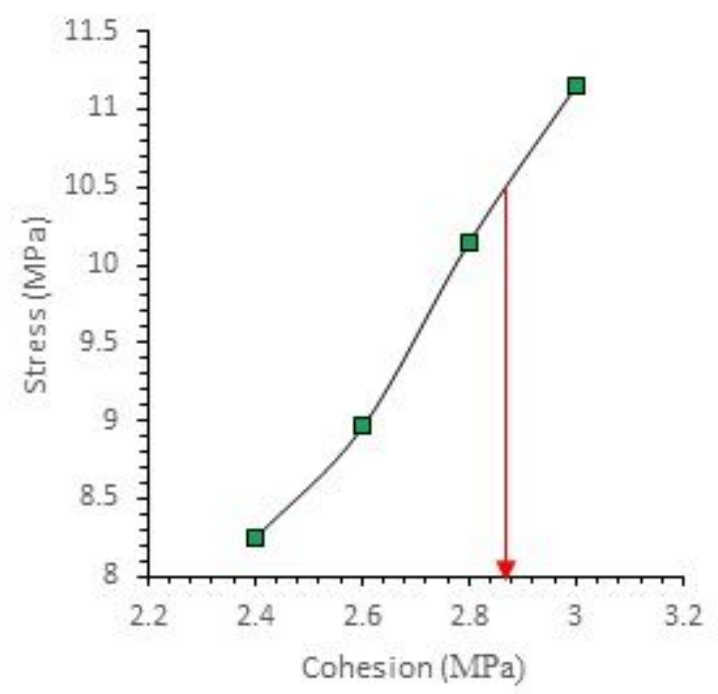

Figure 14

Effect of cohesion on the Unconfined Compressive strength of the synthetic material numerical model

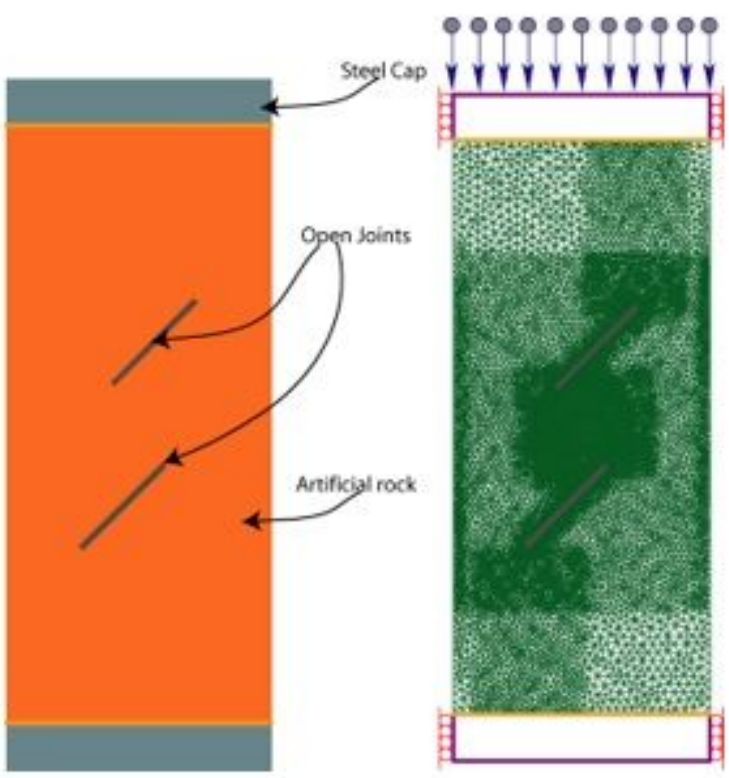

Figure 15

The model, mesh, and boundary conditions used in the numerical model 


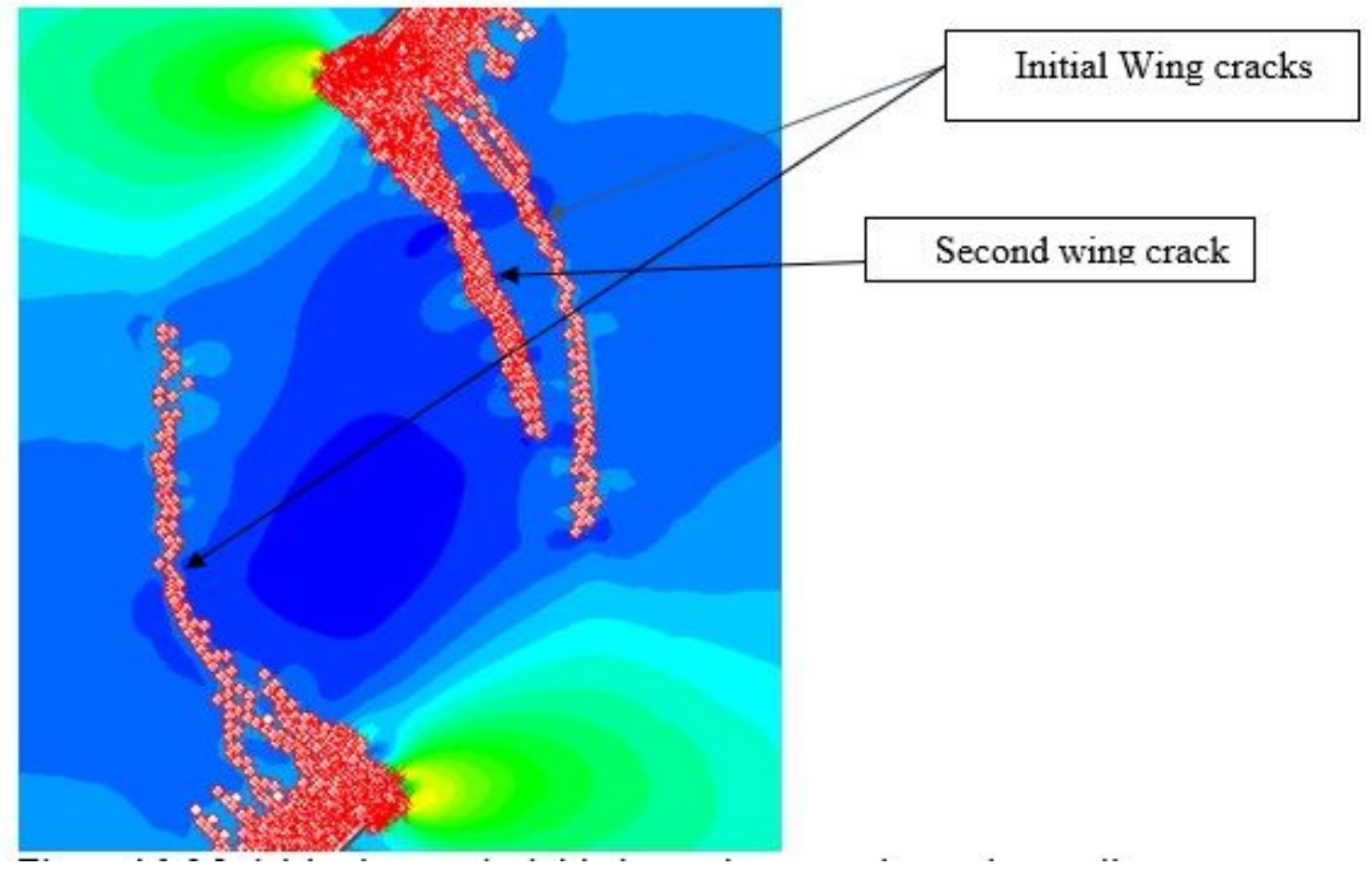

Figure 16

Model 1 wing cracks initiation and propagation under tensile stresses

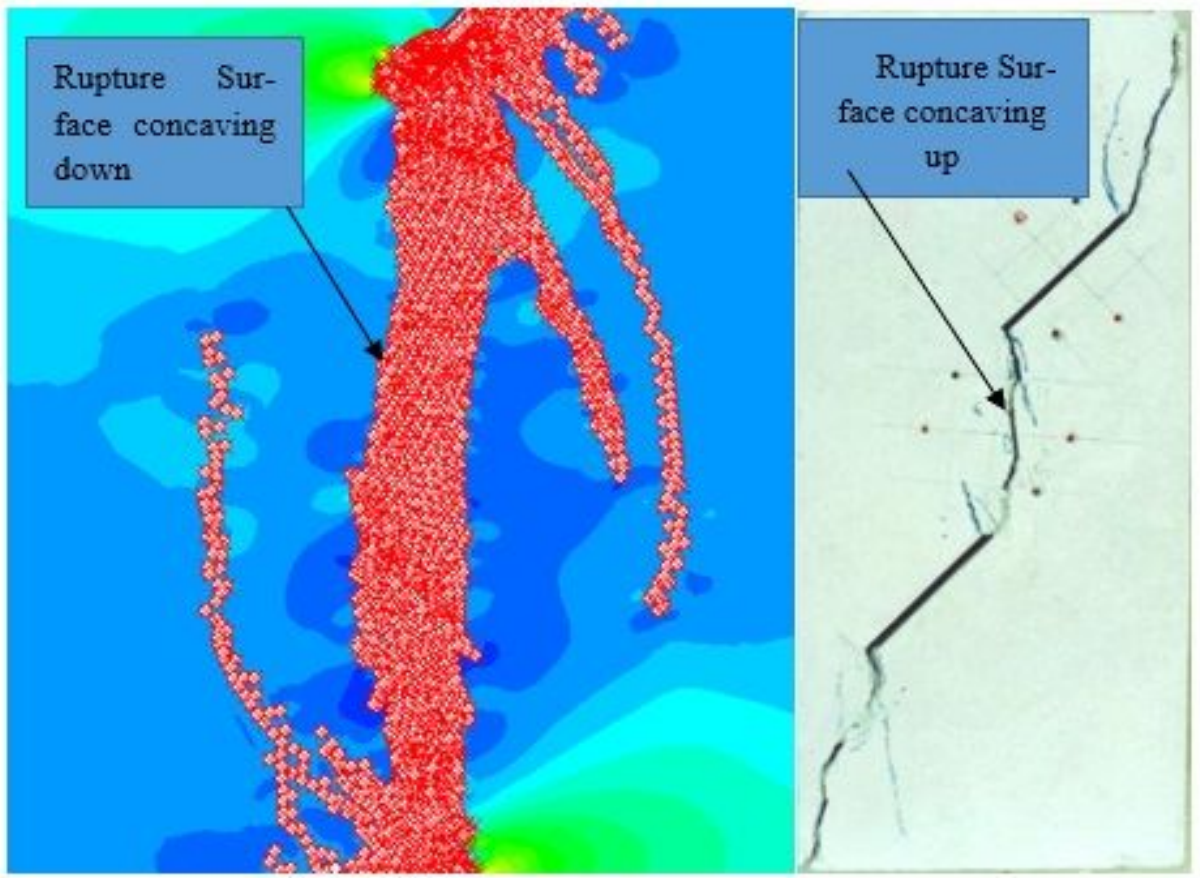

Figure 17

Model 1, rupture surface, and the actual laboratory model 


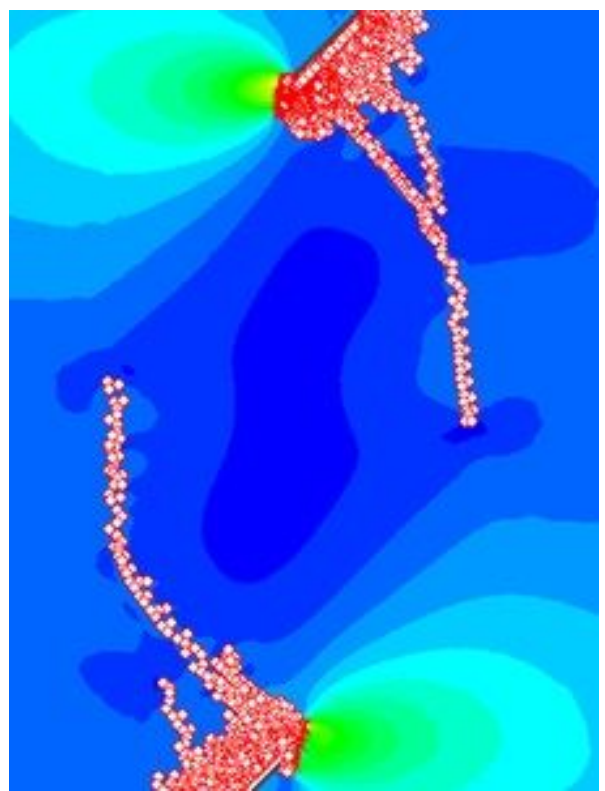

Figure 18

Model 2, wing cracks initiation and propagation under tensile stresses

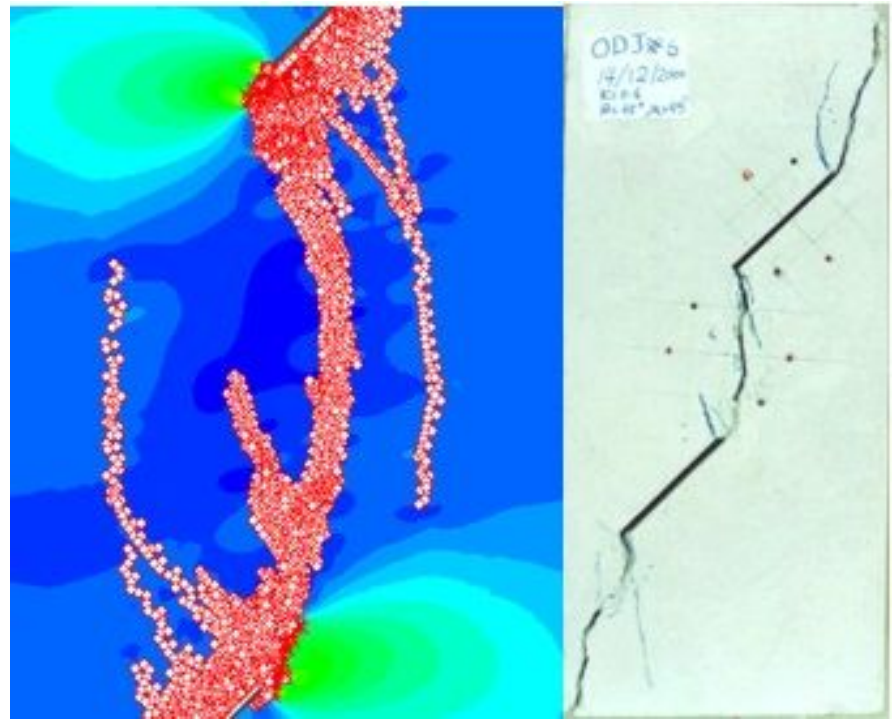

Figure 19

Model 2, rupture surface and the actual laboratory model 


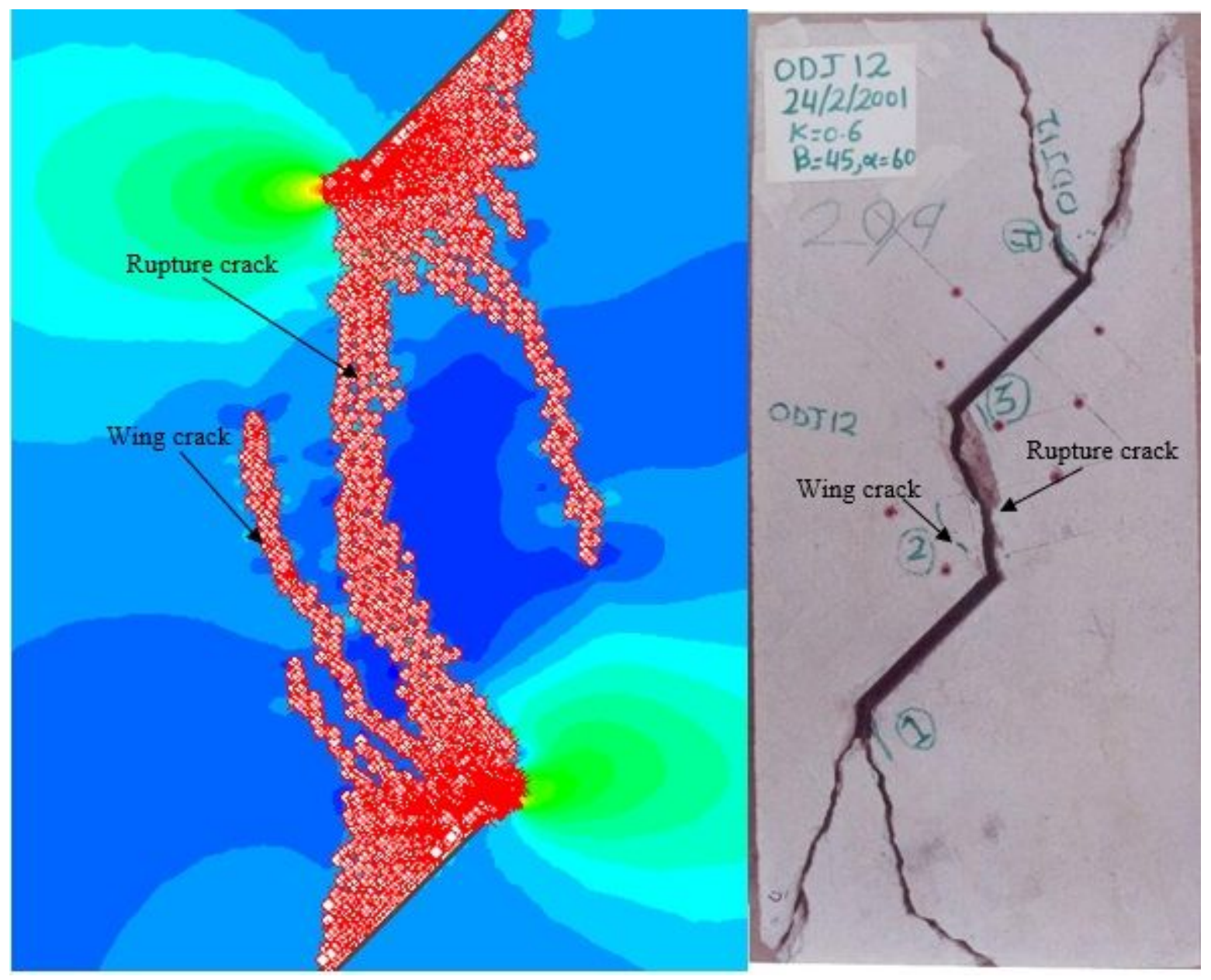

Figure 20

Model 1, rupture surface, and the actual laboratory model 


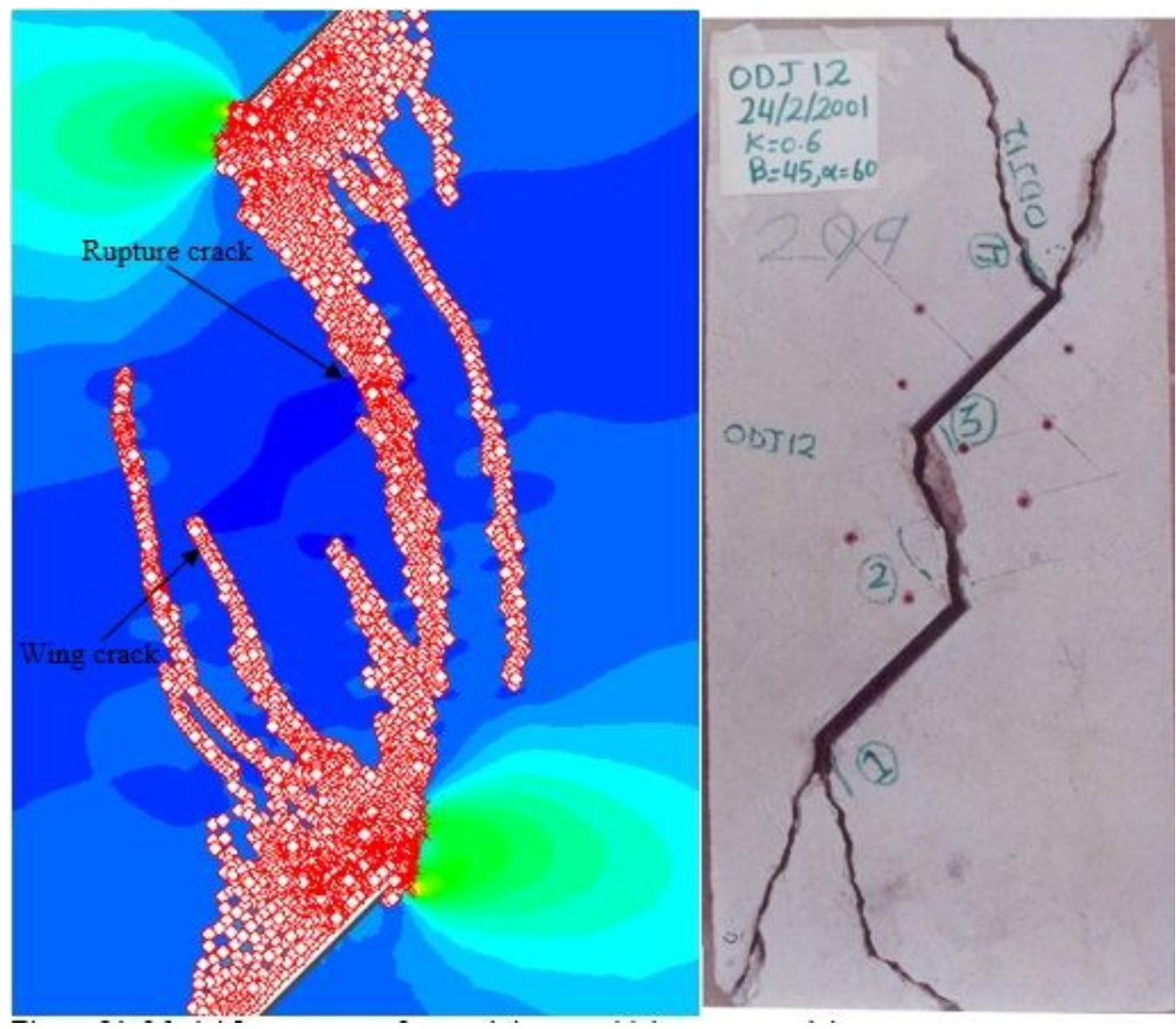

Figure 21

Model 2, rupture surface and the actual laboratory model
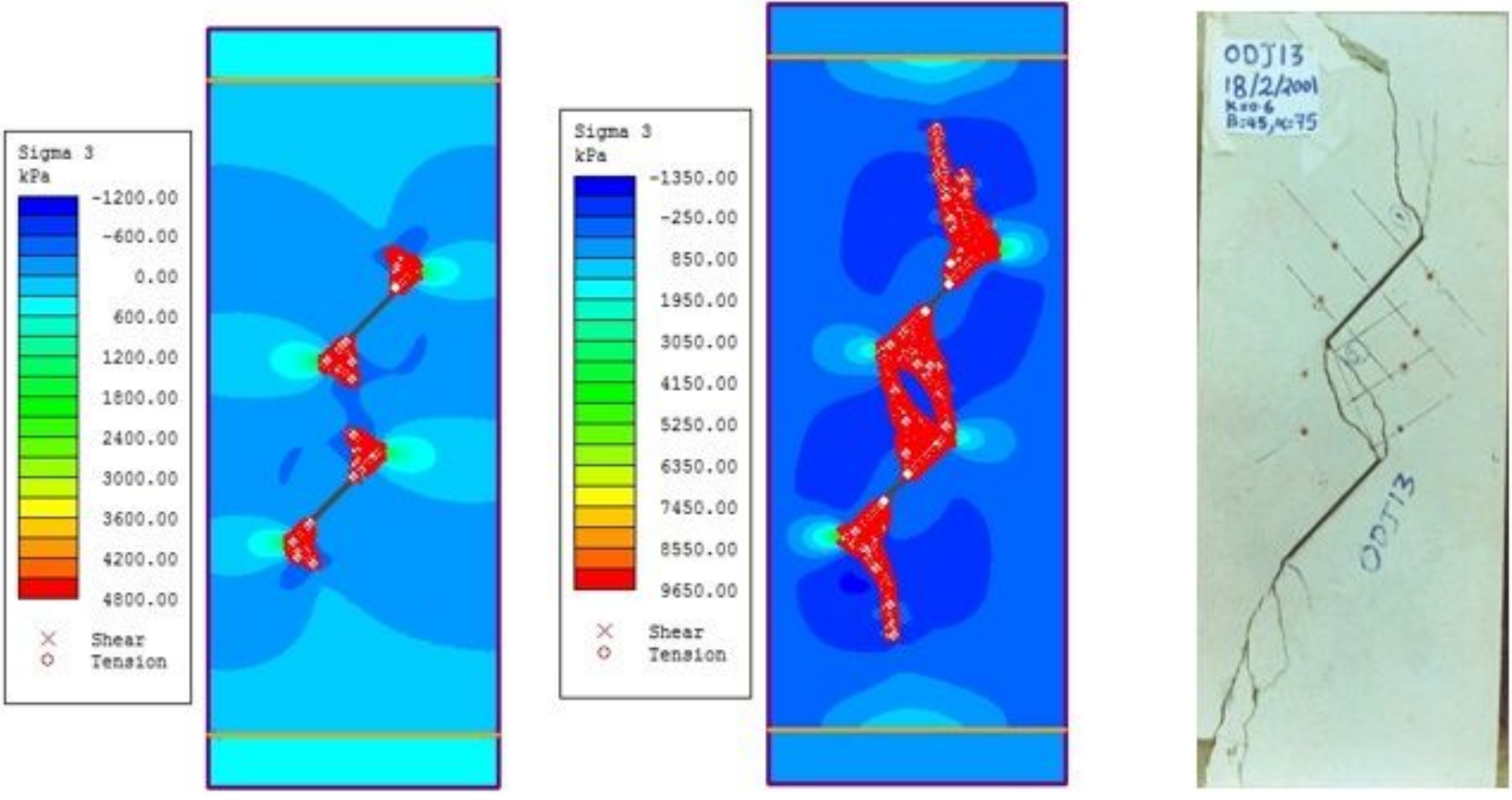

Figure 22

Model 1 crack propagation and coalescence, and minor principal stresses 


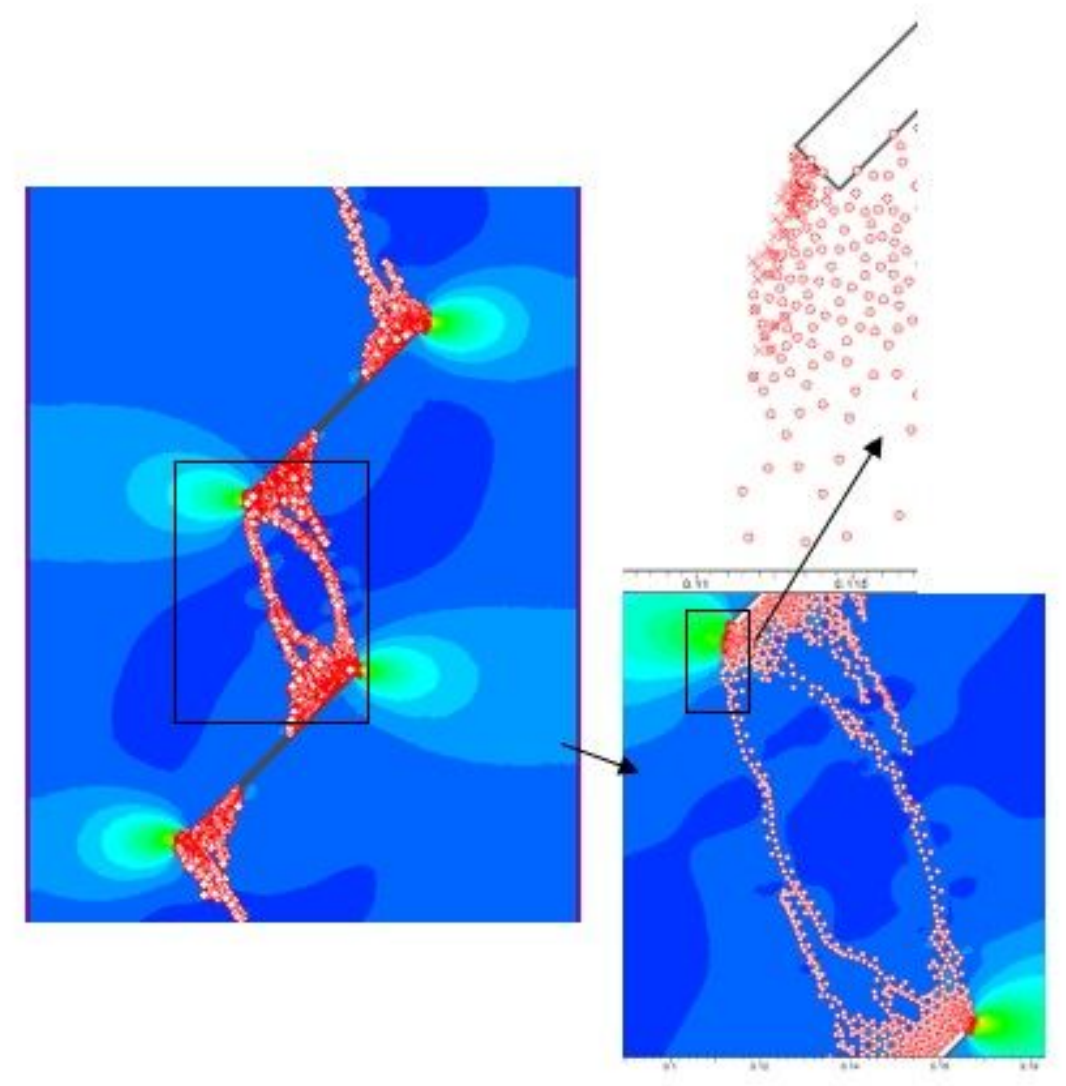

Figure 23

Model 2, yielding elements in the bridge area at failure 

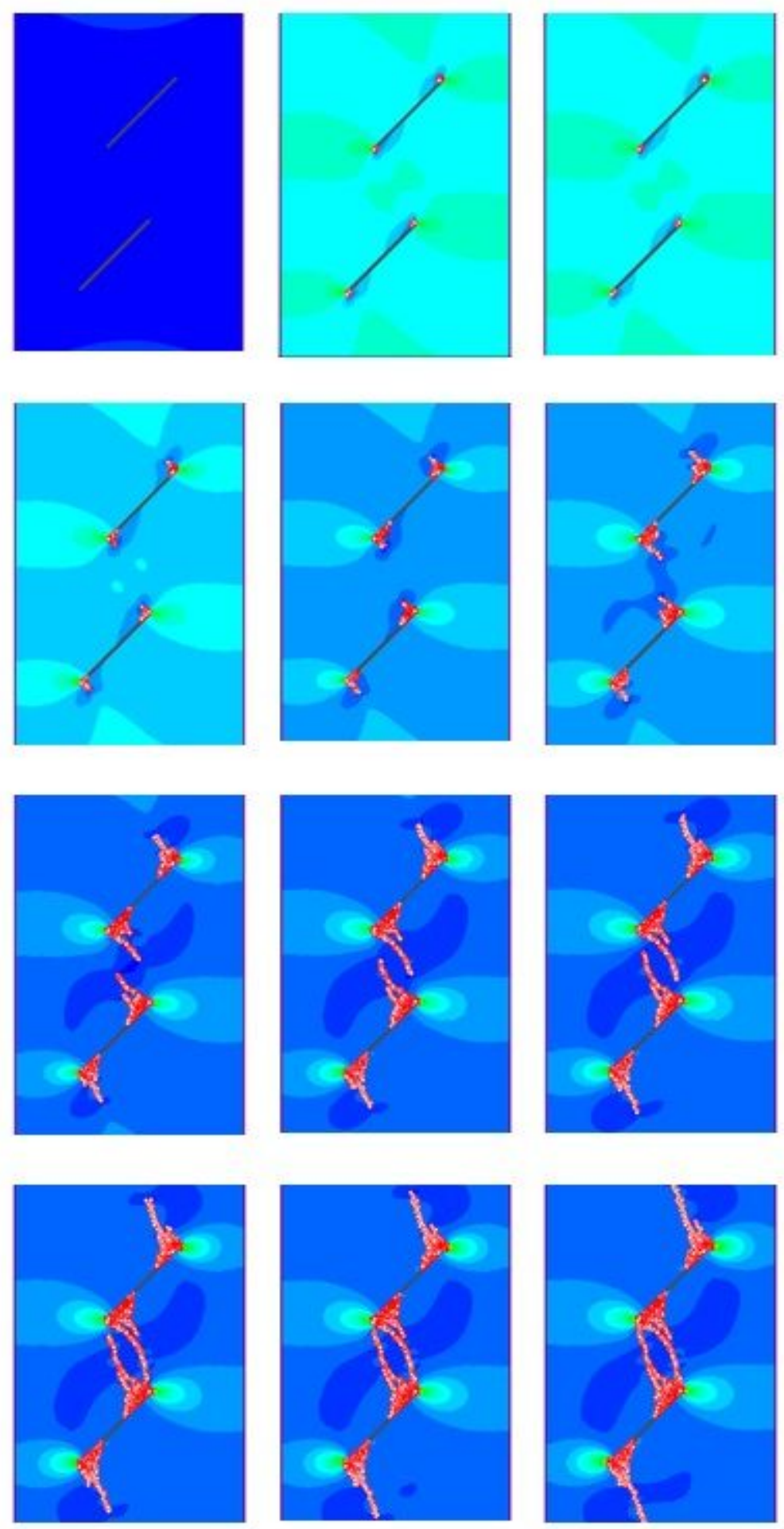

Figure 24

Yielding progress to form a core failure in the bridge 


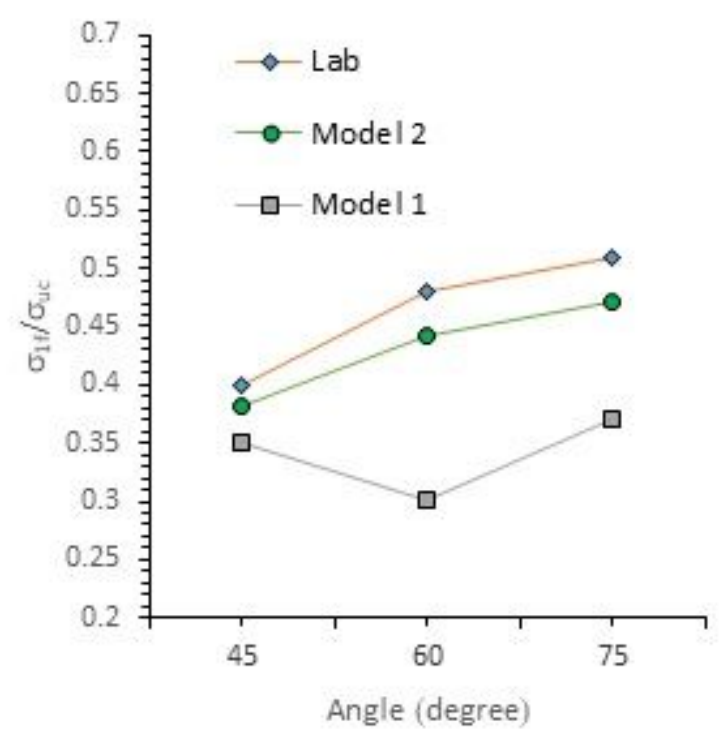

Figure 25

Uniaxial compressive strength for the two models and the laboratory samples

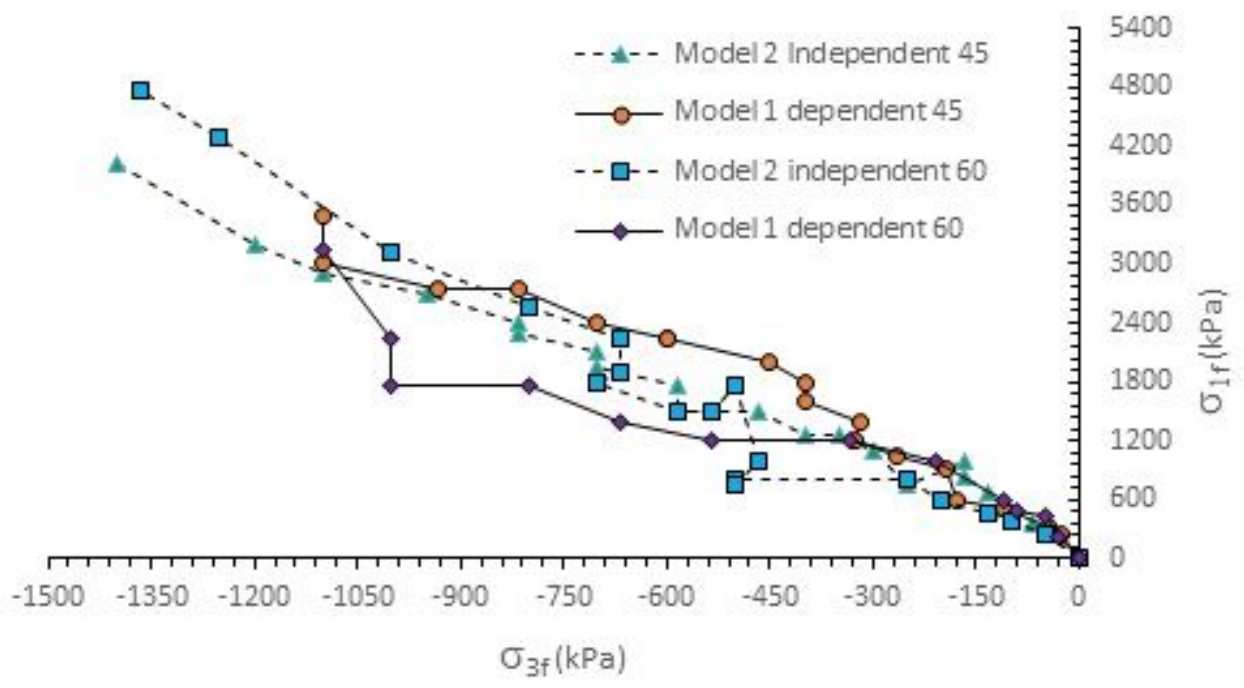

\section{Figure 26}

Stress path for two samples at the bridge area 